\title{
Developing the Global Graduate: How First Year University Students Narrate Their Experiences of Culture
}

Doris Dippold ${ }^{\mathrm{a}}$, Stephanie Bridges ${ }^{\mathrm{b}}$, Sue Eccles ${ }^{\mathrm{c}}$ and Emma Mullen ${ }^{\mathrm{d}}$

${ }^{a}$ School of Literature and Languages, University of Surrey, Guildford, UK;

${ }^{b}$ School of Pharmacy, University of Nottingham, Nottingham, UK;

${ }^{c}$ Executive Business Centre, Bournemouth University, Bournemouth, UK,

${ }^{d}$ Newcastle Business School, Northumbria University, Newcastle, UK 


\section{Developing the Global Graduate: How First Year University Students' Narrate Their Experiences of Culture}

Developing global graduates or global citizens is a goal often expressed in university mission statements. This study draws on Amadasi and Holliday's (2017) distinction of block narratives and thread narratives of culture and applies these to interviews with first year students. It shows that some ability to draw on thread narratives and therefore non-essentialist views of culture is in evidence from the start of students' university careers. Universities need to implement policy and practice to foster the emergence of these abilities and thus enable students to acquire the attributes of a 'global graduate'. This will also ensure that 'internationalisation at home' is not a value-free concept.

Keywords: internationalisation at home, global graduate, essentialism, higher education, critical cosmopolitanism 


\section{Introduction}

According to recent HESA statistics, approximately 43.000 non-UK students studied at UK higher education institutions in 2015-16, joining approximately 1.842.000 UKdomiciled students. The latter group is also not at all homogenous, as a sizeable fraction of UK domiciled students describe themselves being part of a number of ethnic minority groups. This ratio of national versus international students is typical across a number of other countries such as Australia and the US.

This everyday diversity experienced on campus has led to many higher education institutions formulating internationalisation strategies or including reference to internationalisation in their strategic plans. Many of these make reference to the 'global graduate', the 'global citizen' or 'global citizenship'. For example, the new global strategy of the main author's institution, the University of Surrey (University of Surrey, 2017) states "building strong and productive partnerships with the wider community as active, responsible and committed global citizens" as aspirational aim. However - and quite typically of similar corporate strategies and plans (Dippold, 2015) - there is no definition of what constitutes 'global citizenship' or a 'global graduate'. The University of Surrey's strategic plan for instance names business engagement, alumni donations, international rankings and increases in international student numbers as measures of student success, but does not mention how success in developing global citizens or global graduates might be measured, or how indeed the concept may be defined.

This paper starts by describing the attributes associated with these terms through reference to the academic literature and a number of competency frameworks. It will then go on to introduce Amadasi \& Holliday's (2011) distinction of block and thread narratives of culture which will underpin the analysis of interviews with first year undergraduate 
students from four different universities and subject areas. The paper closes with a discussion of implications for university policy and practice.

\section{Literature review}

\section{The qualities of the global graduate: defining the concepts}

Whilst higher education policy makes little attempt to provide definitions, the academic literature has described the qualities of a 'global citizen' or 'global graduate'. For example, Leask (2015) defines global citizenship as a mindset which includes "a way of thinking about ourselves and others, awareness of how our actions affect others, respect and concern for their well-being, and a commitment to certain types of action to address world problems" (p. 60). The list of qualities of a global citizen contains, amongst other items, "the ability to [...] consider issues from a variety of perspectives", "awareness of their own cultures and its perspectives on other cultures and their perspectives", "appreciate the complex and interacting factors that contribute to notions of culture and cultural relationships" (p. 56).

Similar qualities are expressed in various competency frameworks, which have in common an emphasis on flexibility and the ability to consider different perspectives, encompassed in terms such as 'ethnorelative view' (Deardorff, 2006), 'flexible thinking' with the subcategory of 'willingness to challenge stereotypes and modify assumptions' (Global People, 2010), ‘embracing multiple perspectives' (Diamond, Walkley, Forbes, Hughes \& Sheen, 2011) or ‘openness’ (Higher Education Academy, 2014).

\section{The development of global graduate qualities and university realities}

However, research suggests that the contemporary university is still quite far removed from promoting these ideals in practice. Studies report a general lack of contact between 
home and international students (Brown, 2009; Tian \& Lowe, 2009), leading to international students feeling stereotyped, marginalised and silenced, including in academic matters such as group work (Gabriel \& Griffiths, 2008; Montgomery, 2009; Robinson, 2006; Turner, 2009; Volet \& Ang, 1998). As a result of them being denied equal participation rights, international students engaged in acts of 'self-othering' and gave up trying to make contributions to the group. Generally, these experiences led to international students relying on national student friendship networks (e.g. Housee, 2011, Schweisfurth \& Gu, 2009).

Local or home students are not immune to these behaviours and feelings (Dunne, 2009; Peacock \& Harrison, 2009). Studies show that local students tend to define culture as nationality, perceiving international students as culturally different. Anxiety, effort, language and the possibility of having to compromise their identity by not being able to express themselves openly during an encounter influenced the nature of their interactions with international students. Peacock \& Harrison (2009) suggest that this fear of mixing with international students may be nurtured by students' anxieties about offending others. Signs of mindfulness and self-censorship become evident, as students make conscious and effortful attempts to avoid stereotyping. In addition, language is a particularly powerful factor which exacerbates the power differential and, consequently, the schism between home and international students, with perceived linguistic and cultural barriers and prejudiced attitudes towards international students being strongly linked (SpencerRodgers \& McGovern, 2002).

Henderson (2011) suggests that the modern university does not provide opportunities to develop global graduate qualities thus:

"The concept of 'internationalisation at home' is partially founded on a belief that shared spaces can lead to improved intercultural skill and understanding. However, this study 
suggests that more work is needed to provide a managed context in which intercultural encounters are positive, meaningful and non-threatening. [...] This study found little evidence that home students shared the values enshrined in "internationalisation at home", nor that these have been effectively articulated to the students" (p. 897)

This paper will discuss to what extent first year students display the qualities and abilities associated with global citizenship and the global graduate (see above) in their narratives of their experiences of culture. In doing so, we will explore how universities can implement policy and practice to develop these qualities and ensure 'internationalisation at home' is not a value-free concept.

\section{Talking about (experiences) of culture: analytical frameworks}

\section{Block and thread narratives of culture}

In order to achieve these aims, we will investigate to what extent students' narratives create so-called 'thread narratives' or 'block narratives' (Amadasi \& Holliday, 2017). Block narratives represent essentialist views of culture, which "restrict, separate, and maintain essentialist boundaries" (p. 258). In contrast, thread narratives align with nonessentialist views of culture and "resonate across boundaries to reveal shared cultural creativity" (p. 258). The general characteristic of essentialist/neo-essentialist and nonessentialist views of culture, as defined by Holliday (2011), are summarized below (table 1):

Table 1 near here 
The ability to create thread narratives and describe culture in non-essentialist terms is thus aligned with the characteristics of global citizenship outlined above (e.g. willingness to challenge stereotypes, openness, ability to embrace multiple perspectives). It is also aligned with Holliday's (1999) concept of a 'small culture' which is non-essentialist in that it "relates to cohesive behaviour in activities within any social grouping", the interpretation of which depends on "emergent behaviour within that grouping" (p. 241) rather than national or ethnic features.

Applying these concepts to the analysis of interviews with newly arrived postgraduate students in the UK, Amadasi \& Holliday (2017) found that the participants drew on both block and thread narratives, and that these can be competing. In addition, the way questions were asked, was shown to profoundly influence these narratives as interviewers drew on their own experiences and views. In another study, Colvin, Volet \& Fozdar (2014) found that Australian 'home' students conceptualisations of culture, and the extent to which they were ethnocentric (and thus based block narratives) or ethnorelative (based around thread narratives) were strongly related to students' perceptions of diversity (segregated and impermeable vs. integrated and permeable) and their own experiences of intercultural interactions.

\section{Personal trajectories, identity and co-construction}

This study explores students' narratives of culture in relation to both issues touched upon above. We take into account the link to personal experiences of culture (Colvin et al., 2014). This is encapsulated in Holliday's concept of 'personal trajectories' such as family, peers, profession or travel which shape individuals' responses to larger cultural practices and resources as part of the formation of small cultures (Holliday, 2016, p. 4). 
Furthermore, we explore the discursive construction of cultural narratives in the context of the research interview. As Mann (2011) purports, 'interview talk is inevitably a coconstruction between the interviewer and interviewee' (p. 9), and thus requires a focus on the interviewer, the interactional context and the process of the interview. If interviews are thus seen as a 'social practice' (Talmy, 2011), there is a recognition that data are collaboratively produced.

In deploying this perspective for the analysis of the data, we are drawing on the idea that students' identities, as expressed through their narratives of their cultural experience, are discursively constructed, negotiated between speakers, indexed through language and potentially contested (Bucholtz \& Hall, 2005; De Fina, 2015; Young, 2008). Studies on discourses of culture and cultural difference in higher education settings have previously shown evidence of this. Lee (2015) illustrates how, in the English as a second language classroom, an instructor facilitated a topical discussion starting from an 'assumption of difference' and 'expectation of cultural otherness' (p. 85). A study by Sterzuk (2015) shows evidence of identity co-construction and shift. For example, a Nigerian student started positioning himself as a non-native speaker as a result of interactions with Canadian peers who positioned themselves as owners and custodians of correct English. In the analysis section, we make continuous reference to how interviewers, through their questioning, contribute to the co-construction of narratives of cultural experience.

\section{Methodology}

\section{Research Questions}

This study is part of a research project on first year students' transition into higher education, focusing on their sense of belonging, their perceptions of cultural diversity, 
their practices of working together in groups and their conceptualisations of employment and the world of work. This study seeks to investigate how first year university students talk about their experiences of culture, and to what extent they orient to threat and block narratives. In particular, we will look at the following sub questions.

- What 'personal trajectories' do students draw on?

- What categories of description do they deploy?

- What language do they deploy in their conceptualisations?

\section{Methods}

The research was conducted at four different sites, each representing a different discipline of study (table 2). All have a diverse intake of students.

The first phase of interviews was held during the first four years of the academic year. Students participating were re-invited to a follow-up interview in the later half of the second semester in an effort to gain an updated understanding of their personal, social and educational trajectories. In this paper we will draw on examples from both interview phases.

Full ethical approval was received for the study and students informed via participation information sheets and consent forms of the nature of the study, their participation and that all data would be anonymised.

The interviews were conducted by the co-authors of this paper at three of the university sites. As the main author of the paper was on maternity leave, the interviews on the fourth site were conducted by their maternity cover, a post-viva $\mathrm{PhD}$ student in Sociology. Interviewers thus represent a wide range of research experience and interests, in particular in 'culture' as the main focus of this paper. The interviews took place in the 
respective researchers' offices and were audio-recorded. Their average duration is 32 minutes.

\section{Participants}

Participants were recruited from compulsory first year modules in the respective courses. They were invited through a short introductory talk in an early session, which was then followed up by e-mail invitations and individual arrangements through email. The sample was thus self-selective, with the project attracting students which showed an active interests in the research. Our analysis does not suggest that this had a major impact on the results of the research.

A total of 70 interviews were conducted, with 45 from the first phase of data collection and 25 from the second phase of data collection (see table 2).

Table 2 near here

The students interviewed represent a mix of origins, experiences and personal trajectories: we interviewed a mix of UK, other EU and international students. Some UK and EU students were from ethnic minorities, whilst some international students had received high school and college education in the UK. As it is common in ethnomethodological approaches, we will make no reference to students' origins unless they themselves orient to these categories in the talk itself (Benwell \& Stokoe, 2006, p. 36).

\section{Data analysis}

All interviews were audio recorded and transcribed verbatim. Each member of the research team then conducted a thematic analysis of a sub-set of the data. The themes were subsequently discussed and nine overall themes identified. Individual members of 
the team then took charge of the themes in which they had the most expertise and coded all data relating to the respective theme. The research question which is pursued in this paper emerged from this process.

When scrutinising the data, we looked not only at the 'big stories' told by participants, but also the 'small stories' hidden in the data, which revealed themselves through their narratives and the language they used (see Georgakopoulou, 2015). We also noted that, rather than taking a neutral stance, some of the interviewers brought their own subjective experiences into the interview. Rather than dismissing these interventions as undue ways of influencing the interviewees' answers, interviewers' questions and prompts provided a perspective of co-construction and the impact of the interviewer on the interview talk.

\section{Findings from the data}

Upon analysis of the data, it became clear that few interview extracts can be classified into thread or block narratives in a clear cut manner. However, we have found examples in the data in which block narratives are dominant.

\section{Predominant block narratives}

In example 1, the interviewer introduces the somewhat loaded word 'challenges' in a question centring on diversity through language and culture, therefore predetermining categories on which the students' answer might centre.

\section{Example 1}

Interviewer Have you found any challenges through diversity, be it of language, culture, ability?

Bella Not many challenges really. I've found it really interesting to meet new people. I think some students that are international students, when you are 
trying to talk with them, occasionally there'll be a slight language barrier, maybe they don't understand something, or they're not quite as clued up on certain things and you question, why aren't they like me [laughs]? Or why don't they know that? But nothing too challenging really. I think we all get along really well, and although they've had a different style of education, they're still at quite a similar level. The first semester brought everyone to the same point as well, which was a good thing.

Although Bella initially denies finding many challenges in living and working with others, she then moves on to position herself as part of a group whose language skills, knowledge/understanding and attitudes are different to those which are part of a group she labels 'international' students. This characterises this extract narrative which is predominantly a block. The discourse of difference is underwritten additionally by the use of the personal pronoun 'they' which is deployed to delineate group membership, and the rhetorical question "Why aren't they like me?"

Whilst the narrative of difference in this example appears to be a co-construction between the interviewer and the interviewee, Bella's use of strategies to soften her account, such as the denial of the existence of challenges, the upgrading of the expressed interest in meeting new people, the laughter after the 'Why aren't they like me' question and the insistence of getting along quite well and having arrived at a same level can be read as part of an attempt to make her account politically acceptable and of selfcensorship (see Peackock \& Harrison, 2009). In addition, these strategies can also be seen as a way of distancing herself from the interviewers' focus on challenges and of projecting a non-essentialist or cosmopolitan outlook. 
Nationality and language are frequently the factors through which students structure their narratives, as in the following examples from an interviews with Brad and Anna.

\section{Example 2}

Brad There's only one who's in my group. There's loads of people I've not actually met. I think there's a few handful more international students. But there's only one that's actually in, like, my- like, of the twenty students I work frequently with.

Interviewer And what- what nationality is she?

Brad She's Chinese. Yeah. I [inaudible] - I think she's struggling a little bit. She speaks English fairly well but I think other people haven't been quite so open and quite - I'm not [inaudible], I don't want to say unwelcoming but, you know, not quite as approachable as what they probably should be. So, I know she's- she struggles some of the time. Like, in group work, she's the o- the shy one who sort of stays and then just lets people take the lead in there. I know some of [inaudible] lectures and seminars, she'll be on her phone. And if you- you look over, you can see it's all in Chinese. Maybe she feels a bit isolated perhaps from different students. And I've tried speaking to her and she is- she's lovely. She really is. But you- you can sense she's a bit shy. And obviously, when you're shy in a new environment, that's hard enough. But when you don't speak the language quite as well and other people are completely dif-different to you, not just a different, like, area of the country but a different nationality altogether, it can be quite difficult. And, yeah. I do feel sorry for her at times. 
In this example, Brad initially describes his engagement with international students in general, ending in an identification of one international student he frequently works with. It is then again the interviewer who forces a national identification of the individual 'what nationality is she?' Brad subsequently identifies the class mate as Chinese and continues by describing her behaviours and purported character traits (shy, a follower, disengaging from the English speakers in the group).

He finishes his account by naming assumed group characteristics, such as the (lack of) language skill and nationality, signposted by the impersonal pronoun 'you': 'When you don't speak the language quite as well and other people are completely dif-different to you, like, area of the country but a different nationality altogether, it can be quite difficult'. Brad also expresses regret and compassion for how he feels students who speak different languages and have different nationalities are being treated by others and for the struggles of the individual Chinese student.

What is notable in this example is that the use of the personal pronoun 'you' creates a sense of outsider description of the other group and thus juxtaposition to the group he would consider himself belonging to. The identification of the classmate as part of a national group (Chinese) after the interviewer's prompt makes this another coconstructed block narrative in which an individual's nationality is used to describe differences to the majority group and difficulties resulting from these differences. Nevertheless, by acknowledging the individuality of the particular student described and quoting other possible root causes for the observed behaviours ('maybe she feels a bit isolated perhaps from different students'), Brad also introduces a perspective which, if developed, could reshape the narrative into a thread. In addition, Brad emphasizes the fact that he has tried to establish rapport with the student and likes her ('I've tried speaking to her and she's lovely'). 
Example 3 shows evidence of a student rejecting the interviewer's attempt to impose a cultural identity. However, she does so under the premises of a block narrative.

\section{Example 3}

Interviewer No, it's fine, it's so interesting because you, it's so hard to trace like what your background is because I'm Polish and you can tell I'm Polish because I was raised in Poland, I spent that twenty one years of my life, but you've got such an interesting kind of, kind of life trajectory and and it's like like when I talk to you it's really hard for me to think where, like where exactly, where, where are you coming from because you're such a happy person. You know, because I'm Eastern European, I'm a typical Eastern European complaining, not happy with my life enough, but you're so different. You kind of, you're Spanish but there are some kind of traces of of Eastern European person, kind of cultural elements that I can sense in you but it's such a nice combination.

Anna To be honest, there is a thing that I really really like from England because everybody's considering me Spanish and that is like so, I don't know, I'm sorry for say this, but I hated Russia for like maybe fifteen years of my life because this image, Europeans and just America, USA, all of this have like such a bad image of maybe East Europe and Russia, so there is this kind of hate, so I always try to be like Spanish and try to like get involved and stuff, I've never [inaudible] or stuff but, my friend also he had a Russian, Russia, Russia and he been considering me Spanish and that is like so so nice and I'm now feeling like, I don't know, even though I still have the Russian background and stuff, but they, my friend he tells me but you're 
Spanish and that is, I feel Spanish. [...] Because I have been raised there and all the politics, I know what is going on. [...] All of my education has been based in Spain so the thing that I have from Russia are just my parents and my passport, that's all.

In an earlier part of the interview, Anna had discussed her personal life trajectories with the interviewer. Whilst born in Russia, she has lived the majority of her life in Spain. The interviewer starts this part of the interview by an extended narrative in which she describes herself as 'typical Eastern European' and suggests that Anna does not share the purported attributes of an Eastern European, which are 'complaining, not happy with my life', but instead combines Eastern European and Spanish character traits.

In her answer, Anna clings on to block narratives of culture in that she emphasizes the interconnection between being Spanish and purported Spanish character traits ('so I always try to be like Spanish and try to like get involved and stuff', 'he had been considering me Spanish and that is like so so nice'). In addition, she strongly rejects being associated with anything Russian ('I hated Russia for like maybe fifteen years of my life because this image'), not recognising the possibility of ambivalence of cultural identity. Her rejection of the interviewer's attempt to associate her character traits with her Russian heritage ('All of my education has been based in Spain so the think that I have from Russia are just my parents and my passport, that's all') should be seen as part of this block.

\section{Introducing thread narratives}

In example four, Steven reflects on how work abroad has shaped his experience of culture.

\section{Example 4}


Steven I worked quite extensively in the Middle East, and working with different
S cultures is sort of second nature. I was based out there for- for months on end working in the logistics site. So working with Arab cultures, if you like, is completely different to how- how we would work. And understanding how they operate is essential to making sure that our aims and our missions are- is... How shall I put this, you've got to understand how to motivate cultures in order to achieve the aim, because I'm vbecause I'm Westernised, it doesn't mean that my way is right, or that it's gonna work in their world. So you've got to then try and find that balance to make it work

Interviewer Yeah.

Steven Does that...

Interviewer Yeah, could you talk me through, just back tracking to something you said, could you talk me through how the way that they work is different to ours?

Steven Well...

Interviewer You said it's important to understand how that is different.

Steven The pray times for instance, you know, their religious beliefs dictate certain things. Their weekends are different days to what our weekends are. Their work ethic is strong, hugely strong, but influenced by different factors. So for instance, you could argue that our work ethic, or our main way of- of- of going in the Westernised world is probably monetary etc. I don't know monetary or other ways, but theirs is definitely family, and of value and loyalty based. And once you can start joining them dots up you can start making a bit more of a- an informed decision. 
Steven's account of working in the Middle East prior to applying for university also shows signs of a predominantly essentialist block narrative. He bases his account around geography ('Middle East') and ethnicity ('Arab cultures') and emphasizes differences bin ways of working derived from these categories, as marked by relevant personal pronouns ('we', our' vs. 'they', 'their'). However, rather than underfeeding these examples by merely recounting observed behaviours by individuals or groups, he uses more complex explanations around ethics and values, the understanding of which can help to shape decisions when working with others ('you've got to understand how to motivate cultures in order to achieve the aim', 'one you can start joining them dots up you can start making a bit more of an informed decision'). These explanations can also been seen as an attempt to break through the block to consider alternative possibilities.

In example 5, this is done even more explicitly, featuring active resistance to a block narrative imposed by the researcher.

\section{Example 5}

Charlie There's a boy in my group, in my, like, seminar group, he's from Bulgaria. And he- he's great. He- he's - I don't understand how he- he's done it. He came to England for the first time, two days before he moved in. He's only been studying English for, I think, for the last three years and he's- he's almost fluent. Like, his- it's phenomenal how he's managed to do that. And he just, sort of, gets on with it. [Chuckles] he's ha-happy enough. He likes it here. Not missing Bulgaria. But I'd never met anyone from Bulgaria or eastern Europe. So, that was kind of cool

Interviewer And was there anything about him that you th- that was, sort of, y-you know, if this is the first time you've met someone from eastern Europe, 
what- what were your, sort of, im-im- did you get any sort of sense of what eastern Europeans or Bulgarians are like? I mean, I'm not suggesting he's necessarily typical but...

Charlie No, no. He's - no, he's just - other than his accent, he's- like, he's ...

Interviewer Just he's...

Charlie Another eighteen year old [inaudible]. He's exactly the same as- as me or anyone. Which is- which is kind of weird. You'd always think that being so far away, they'd be completely different. But no, he's not. He's- he's exactly like me. He just - with...

This example features an account by Charlie of one of his classmates. The main categories of description are, initially, nationality and language, with the language of description in itself notably overtly positive, for example when discussing the Bulgarian student's language ability ('I don't understand how he's done it', 'it's phenomenal how he managed to do that') and his own encounters with the student ('that was kind of cool').

However, in the later part of his description of the Bulgarian student, Charlie explicitly resists the interviewer's attempt at introducing fixed associations between behaviours and language and culture ('I am not suggesting he's necessarily typical, but...') with a clear marker of negation ('no') and by using age as a category of description to turn the gaze towards communalities rather than difference ('he is just another 18 year old', 'he's exactly like me'). This suggests that Charlie is able to deploy a thread narrative in which he applies the technique of 'bracketing' (Holliday, 2011, p.31) in that he consciously puts aside potentially prejudiced viewpoints - e.g. nationality - and locates other categorisations. Despite expressing surprise about the non-existence of geographical boundaries as an explanatory variable for behaviours ('You'd think by being 
so far away they'd be completely different'), Charlie 'brackets' the interviewer's description of the student in question as 'Eastern European' and instead foregrounds age.

In example 6, Harry develops a thread in which he deconstructs his experience of international students socialising:

\section{Example 6}

Harry Everyone's in the same situation really. Everyone comes here not knowing anyone and everyone comes here needing to make friends. So, I would say that it's probably quite- just as stressful for someone else as it is for them. By the same token, there are a couple of international students in my flat who I've only seen once. So, there's both sides of the coin I guess in that there are people who are international students that never come out of their room and there are international students that will come and sit with us and socialise normally. So, yeah. There is- there is a slight disparity. But then, I suppose that - it doesn't in my flat but that could happen with British people just the same, that they don't- they don't want to go out and talk. I don't know. I don't know. I haven't- haven't experienced that.

Even though Harry presents socialising as the norm ('sit with us and socialise normally'), his discussion of why some students socialise and others do not draws on communalities between students rather than differences, which is visible signposted by the collective personal pronoun 'everyone' ('everyone comes here not knowing anyone and everyone comes here needing to make friends'). Subsequently, Harry goes on to suggest that there may be British students who do not like to socialise and thus acknowledges individual disposition as the main contributing factor to observable behaviours, rather than language, 
culture or nationality. This example thus fulfils the criteria of a thread narrative which relies on creating "shared meanings" (Amadasi \& Holliday 2017, p. 254).

\section{Talking about cultural experiences: language observations}

In some of the earlier examples quoted, we have already pointed out some of the ways in which students talk about culture. Overtly positive language to describe encounters in situations of linguistic and cultural diversity are frequent occurrences in the data, as shown also in example 7.

\section{Example 7}

Harry Slightly. I mean, not- not as broad a variety as you get here. Where I come from [chuckles] is very- very white, middle class, if I am honest with you. I guess in Kenya I did, whilst I was away. And I really enjoyed that. I- I loved that. It was brilliant. [...] The food [chuckles] the food was great. About the people? I guess their- them- their really laid back attitude. It'sit's...

Interviewer We're too stressed here, are we?

Harry Their concept- their concept of timing is- is something else, you know? You know, m-my timing for this interview today would be Kenyan time. I said I was gonna be here at one, got here about twenty to two. I mean, that would've been- that would be fine out there. That would be totally normal. But over here, it's like 'you- you said you were gonna be here at one. You know, you- you should be here at one.' And over there... 
The first observation here is that Harry deploys strong essentialist constructions characteristic of block narratives when talking about his trip to Kenya during a gap year before starting university. He uses juxtaposing pronouns and adverts ('their', 'here and there'), alluding to separated worlds. In addition however, Harry also deploys many examples of overtly positive language 'I really enjoyed that', 'I loved that', 'their really laid back attitude', 'their concept of timing is something else' and 'the food was great'. The latter two descriptions - food as a cultural artefact, and the uncritical discussion of the purported relaxed attitude to life and timing, in combination with the positive vocabulary is evidence of only superficial experience in interacting with those of a different cultural background, which is something Harry had indeed admitted to in the beginning of the interview.

Owing to the overtly positive language used to describe interactions with the culturally 'other', I have termed examples of this phenomenon 'honeymooning language'. Superficially, interview extracts featuring such honeymooning language could be seen as examples of cosmopolitan views of culture, given that honeymooning language often occurs when students are trying to characterise themselves as culturally interested and open. However, the cosmopolitan attitude is not necessarily underfed by the ability to deploy thread narratives. Consequently, I suggest that examples such as this can be summarized under the label of 'display cosmopolitanism', i.e. a cosmopolitan attitude that is openly displayed - perhaps as a result of the interview context in which the interviewee's face is at stake - but does not include the attributes of a non-essentialist / critical cosmopolitan reading.

The other phenomenon in the data was the use of vague language: 


\section{Example 8}

Interviewer ....at university. So would you say you've learned anything this year from those who may be from a different background than your own?

Amy Well, I guess I've learned a bit about the culture and stuff.

Interviewer Yeah? Yeah.

Amy But, I don't know. I don't really like saying positive stuff about myself 'cause I just...I feel like I'm being a narcissist but...

Interviewer You're not. Don't worry. I promise.

Amy I think I...I've like already got a broad mind. I feel like...

Interviewer Yeah. Yeah.

Amy I'm already open-minded.

Interviewer Okay. So what's been the kind of underpinning of your...the broadness of your mind? Like you broad out luck?

Amy What do you mean by...

Interviewer Is it being pride to university, things like that? Like, where does this come from?

Amy I don't know. I just think it's how I view things, really.

Interviewer Mm-hm. Can you give me an example of where it's come across outside of university? Like even before university?

Amy Well, I was from a s...well, 'cause I came from a town so it's kind of like small and stuff...

Interviewer Uh-huh.

Amy ...so there isn't much, like, effect to it. I mean, we have a lot of Polish people there, but, like...

Interviewer Mm-hm. 

where there's more

Interviewer It's more diverse.

Amy Yeah.

Interviewer Yeah. Yeah.

Amy It's not as divisive...diverse.

Interviewer Yeah.

Amy But there's still like some diversity.

Interviewer Yeah.

Amy Because I remember someone I think...well, I mean, there's French people. Like my friend...sister's friends with some French people and there's, like, Polish people and, like, other people but, like, it's not...it is diverse but it's not as diverse.

Interviewer Yeah. Yeah.

Amy It's, like, kind of closed off...

Interviewer Mm-hm.

Amy ... to society

Example 8 features Amy's reaction to the interviewer's question about learning other students with a different background. Amy suggest that she has learned 'a bit', but it is very notable that she uses a range of markers of vagueness when discussing what she may have learned and her interactions with those representing other cultures (e.g. 'like', 'and stuff'). When asked about the origins of her purported broad-mindedness, Amy is unable to give specific examples ('I don't know') and resorts to saying that this is just a trait of her personality. In the subsequent discussion on Amy's geographical background before 
coming to university, it then emerges that Amy comes from a small town that is not characterised by a diverse population. The few examples of diversity Amy is able to draw on are described by nationality ('French people', 'Polish people'), but these descriptions are again framed by a range of markers of vagueness and hesitation, such as 'like', 'I mean', 'kind of'. Amy also encounters difficulties using the word 'diverse', having to rephrase from 'divisive'.

The outwardly stated openness to other cultures qualifies this as another example of display cosmopolitanism. The personal trajectories which Amy draws on here - being from a small town, having little opportunity for intercultural interactions - do not allow her, as of yet, to develop material for a thread narrative that goes beyond broad national categories and 'big C' culture (see Holliday, 2016, p. 4). However, this example also suggests that a more sophisticated vocabulary may well emerge through additional exposure (see example 4), allowing subsequently for more in-depth cognitive engagement with other cultures. We will discuss the implications from this in the next section.

\section{Discussion}

The data provide a unique insight into students' narratives of their cultural experiences at a time when they start out their university journey and thus, if institutional goals are to be fulfilled, their paths towards becoming a 'global citizen' or a 'global graduate'.

The analysis has revealed that, whilst there is evidence of predominant block narratives which draw on nationality and language as distinguishing features and on boundaries between 'us' and 'them', many examples are fluctuating between block or thread narratives or can be seen as moving towards threads. For example, Brad (example 2) associates one student's behaviour with her being an international student and, upon the 
researcher's prompt, being Chinese, but is also able to provide a more complex analysis of these behaviours. Charlie (example 5) 'brackets' the researcher's categorisation of a student as 'typical Eastern European' and suggests age as a factor of commonality and Steven (example 4) contextualises contrasting behaviours with reference to ethics and values. It is important to acknowledge the role of interviewers as co-creators of these narratives. The analysis of the data here was instrumental in making the authors, most of whom were also interviewers, aware of how their own biases and personal trajectories may have influenced the way they worded initial and follow-up questions and thus the course of students' own narratives. These observations also provided us with an opportune chance to ask whether other processes within the internationalised, neoliberal university - in administration, research and teaching - re-enforce or even create essentialist discourses. For instance, students are categorised and labelled from the outset (as overseas students, international students, EU-students, home students, non-native speakers, native speakers etc.), often for invoicing and administrative, but also for academic purposes. In addition, support mechanisms for language and academic skills tend to be geared towards remedial action for the purported deficiencies of international students and non-native speakers, with a view to them adapting to UK linguistic and academic norms. These practices do not break down barriers; rather, they contribute to the discourse of othering and increase the likelihood of block narratives being applied. Dippold (2015) quotes further examples from the wider HE context in both research and pedagogy, such as a study on Chinese PG students' orientations of learning which makes an implicit assumption that Chinese learners should change their attitudes to learning to comply with UK notions (Turner, 2006) and a pedagogical resource published by the Higher Education Academy (Scudamore, 2013) which promotes an anti-essentialist view, 
but yet includes references to essentialist frameworks based on national cultural differences (e.g. Hofstede's individualism vs. collectivism).

It is therefore only logical to ask how universities can instigate change at institutional level to allow for thread narratives to emerge. We suggest that, following Lee and Anderson's (2009) call for 'pedagogical and theoretical language to end marginalisation' (p. 202), language needs to be at the centre of such efforts, allowing international students to be seen as 'strong agents' rather than 'habitually weak or deficient' (Marginson, 2014, p. 12). In practice, this means a move away from using language which focuses on the deficiencies of specific student groups (e.g. in mastery of language and academic requirements such as essays) as this ascribes these groups with negative labels and delineates them from the majority group. In the context of neoliberalism, its free market strategies and the economic power positions of universities in the Western world, this adds to the potential for 'symbolic violence' which 'reinforces and legitimises inequalities' (Watson \& Widin, 2015, p. 659) such as delegitimising the practices of cultural outsiders and not giving non-native speakers linguistic capital.

A focus instead on developing a strong academic identity (Lee \& Anderson, 2009), linked to academic disciplines or courses of study, would remove the need to label and categorise students into overseas, EU and home students, at least for pedagogic purposes (see Holliday, 2017). In addition, it would encourage the development of a shared disciplinary culture and of the skills needed for discipline- specific communities of practice. It also has the potential to counter deficit discourses in relation to language and academic practices which can lead to language ability being conflated with academic and cognitive ability (Ryan \& Viete, 2009). 
Furthermore, by capitalising on the cultural diversity which is inherent in their own student and staff populations, universities can also support students in developing the vocabulary and language to describe cultural phenomena through thread narratives. This is particularly important given the frequent co-occurrence of the phenomena of vague language and overtly positive language - termed 'honeymooning language' - discussed earlier, which prevents the development of such threads. To do so, universities need to look beyond study abroad and language classes and consider opportunities, in core curricula and beyond, to school students as well as their own staff to break through essentialist boundaries. As one example or such efforts, Harsch and Poehner (2016) present a peer scheme and a concept called 'dynamic assessment' by which students work through critical incidents with the help of peers and a trained mediator. The authors argue that this scheme 'has the potential to elicit relevant cognitive processes and intercultural skills, as well as stimulate the beginning of learning' (p. 485). If universities undertook efforts in this direction, they would be able to go beyond 'façade diversity' (Boli \& Elliott, 2008) at institutional level, address the issues of marginalisation and 'othering' described earlier on and make moves towards 'sustainability', which in relation to higher education has been defined as 'possibilities for complex holistic interconnections and relations between students, teachers and curriculum within which power relations are recognised and difference valued' (Ilieva, Beck, \& Waterstone, 2014, p. 880). On an individual level, initiatives of this kind would help students recognise the enormous potential studying with international classmates provides them which, which at the moment is not a given (Bothwell, 2018). Most importantly however, students would be empowered to develop the attributes that constitute 'global citizenship' or the 'global graduate'. Further pedagogically-focused research will be able to investigate the effect of student- or tutorled interventions on the development of non-essentialist views of culture. In addition, a 
longitudinal study tracking students' development throughout their time at the university, in particular before and after a professional training year or year abroad would be able to identify what factors, if any, in students' academic journeys are able contribute to the development of non-essentialist views and the thread narratives associated with these views.

\section{Conclusion}

In this paper, we have investigated how first year university students deploy narratives to talk about their experiences of culture in the context of a research interview. The paper has revealed that the ability to deploy thread narratives and use non-essentialist conceptualisations of culture is emerging, but not yet fully developed in this group of students. We have thus suggested that universities should put into place measures in both policy and practice to allow students to foster the personal qualities and attributes associated with global citizenship or the global graduate, e.g. the ability to challenge stereotypes, think flexibly and make decisions from the perspective of ethnorelativism. Doing this would help universities to move to a state in which internationalisation is transformative and not merely a symbolic, shop window activity.

\section{Acknowledgements}

The autors wish to thank Marion Heron for providing feedback on an earlier version of this paper. 


\section{References}

Amadasi, S. \& Holliday, A. (2017). Block and thread intercultural narratives and positioning: Conversations with newly arrived postgraduate students. Language and Intercultural Communication, 17(3), 254-269.

Bennet, R., Volet, S. \& Fozdar, F. (2013). "I'd say it's kind of unique in a way“: The development of an intercultural student relationship. Journal of Studies in International Education, 17(5), 533-553.

Benwell, B. \& Stokoe, E. (2006). Discourse and identity. Edinburgh: Edinburgh University Press.

Boli, J. \& Elliot, M. Façade diversity: the individualization of cultural difference. International Sociology 23(4), 540-560.

Brown, L. (2009). A failure of communication on the cross-cultural campus. Journal of Studies in International Education, 13(4), 439-454.

Bucholtz, M. \& Hall, K. (2003). Language and Identity. In A. Duranti (Ed.), A Companion to Linguistic Anthropology (pp. 268-294). Oxford: Basil Blackwell.

Bucholtz, M. \& Hall, K. (2005). Identity and interaction: A sociocultural linguistic approach. Discourse Studies, 7(4-5), 585-614. 
Colvin, C., Volet, S. \& Fozdar, F. (2014). Local university students and intercultural interactions: conceptualising culture, seeing diversity and experiencing interactions. Higher Education Research \& Development, 33(4), 440-455.

Deardorff, D. (2006). Identification and assessment of intercultural competence as a student outcome of internationalization. Journal of Studies in International Education, 10(3), 241-266.

De Fina, A. (2015) Narrative and Identities. In A. De Fina \& A. Georgakopoulou (Eds.), Handbook of narrative analysis (pp. 351-368). Chicester: John Wiley \& Sons.

Dervin, F. (2010). Assessing intercultural competence in language learning and teaching: A critical review of current efforts in higher education. In F. Dervin \& E. Suomela-Salmi (Eds.), New approaches to assessing language and (inter-)cultural competences in higher education (pp. 157-173). Bern: Peter Lang.

Diamond, A., Walkley, L., Forbes, P., Hughes, T. \& Sheen, J. (2011) Global Graduates: Global Graduates into Global Leaders. Retrieved from National Centre for Universities and Business website:

http://www.ncub.co.uk/index.php?option=com_docman\&view=download\&category_sl $\underline{\mathrm{ug}}=$ publications \&alias $=42$-global-graduates-into-global-leaders $\&$ Itemid=2728.

Dippold, D. (2015). Classroom interaction: The internationalised Anglophone university. Basingstoke: Palgrave. 
Dunne, C. (2009). Host students' perspectives of intercultural contact in an Irish university. Journal of Studies in International Education, 14(2), 222-239.

Gabriel, Y, \& Griffiths, S. (2008). International learning groups: Synergies and dysfunctions. Management Learning, 39(5), 503-518.

Georgakopoulou, A. (2015) Small stories research: methods - analysis - outreach. In A. De Fina \& A. Georgakopoulou (Eds.), Handbook of narrative analysis (pp. 255-271). Chicester: John Wiley \& Sons.

Global People (2010). Internationalisation in the UK higher education sector: a competency-based approach. Retrieved from University of Warwick website: https://www2.warwick.ac.uk/fac/cross_fac/globalpeople/resourcebank/gppublications/in ternationalisation_in the uk.pdf.

Harsch, C. \& Poehner, M. (2016). Enhancing student experiences abroad: the potential of dynamic assessment to develop student interculturality. Language and Intercultural Communication 16(3), 470-490.

Henderson, J. (2011). New and not so new horizons: brief encounters between UK undergraduate native speaker and non-native speaker Englishes. Language and Intercultural Communication, 11 (3), 270-284.

Higher Education Academy (2014). Internationalising higher education framework. Retrieved from Higher Education Academy website: 
https://www.heacademy.ac.uk/system/files/resources/internationalisingheframeworkfina 1.pdf.

Holliday, A. (1999). Small cultures. Applied Linguistics, 20(2), 237-264.

Holliday, A. (2011). Intercultural Communication and ideology. Los Angeles: Sage.

Holliday, A. (2013). Understanding intercultural communication: negotiating a grammar of culture. London: Routledge.

Holliday, A. (2016). Revisiting intercultural competence: Small culture formation on the go through threads of experience. International Journal of Bias, Identity and Diversities in Education, 1(2), 1-13.

Holliday, A. (2017). PhD students, interculturality, reflexivity, community and internationalisation. Journal of Multilingual and Multicultural Development, 38(8), 206-218.

Housee, S. (2011). What difference does 'difference' make? A discussion with ethnic minority students about their learning experience in higher education. Learning and Teaching, 4(1), 70-91.

Huang, J. (2014). Autonomy, agency and identity in foreign language learning and teaching. Bern: Peter Lang. 
Leask, B. (2015). Internationalizing the curriculum. Abingdon \& New York:

Routledge.

Lee, E. (2015). Doing culture, doing race: Everyday discourses of 'culture' and 'cultural difference' in the English as a second language classroom. Journal of Multilingual and Multicultural Development, 36(1), 80-93.

Lee, J. \& Anderson, K. (2009). Negotiating linguistic and cultural identities: theorizing and constructing opportunities and risks in education. Review of Research in Education, $33(1), 181-211$.

Mann, S. (2010). A critical review of qualitative interviews in applied linguistics. Applied Linguistics, 32(1), 6-24.

Marginson, S. (2014). Student self-formation in international education. Journal of Studies in International Education, 18(1), 6-22.

Montgomery, C. (2009). A decade of internationalisation: Has it influenced students' view of cross-cultural group work at university? Journal of Studies in International Education, 13(2), 256-270.

Peacock, P. \& Harrison, N. (2009). "It's so much easier to go with what's easy":

'Mindfulness' and the discourse between home and international students in the United Kingdom. Journal of Studies in International Education, 13(4), 487-508. 
Robinson, S. (2006). Reflecting on the 'International group working experience': A study of two MBA programmes. International Journal of Management Education, 5(2), 3-14.

Schweisfurth, M. \& Gu, Q. (2009). Exploring the experiences of international students in UK higher education: Possibilities and limits of interculturality in university life. Intercultural Education, 20(5), 463-473.

Spencer-Rodgers, J. \& McGovern, T. (2002). Attitudes towards the culturally different: The role of intercultural communication barriers, affective responses, consensual stereotypes, and perceived threat. International Journal of Intercultural Relations, 26(6), 609-631.

Sterzuk, A. (2015) 'The standard remains the same': Language standardisation, race and othering in higher education. Journal of Multilingual and Multicultural Development, 36(1), 53-66.

Talmy, S. (2011). The interview as collaborative achievement: Interaction, identity and ideology in a speech event. Applied Linguistics, 32(1), 25-42.

Tian, M. \& Lowe, J. (2009). Existentialist internationalisation and the Chinese student experience in English universities. Compare: A Journal of Comparative and International Education, 39(5), 659-676. 
Turner, Y. (2009). Knowing me, knowing you, is there nothing we can do? Pedagogic challenges in using group work to create an intercultural learning space. Journal of Studies in International Education, 13(2), 240-255.

University of Surrey (2017). The Surrey Advantage. Corporate Strategy 2017-2022. Retrieved from University of Surrey website:

https://www.surrey.ac.uk/sites/default/files/corporate-strategy-2017-2022.pdf.

Volet, S. \& Ang, G. (1998). Culturally mixed groups on international campuses: An opportunity for inter-cultural learning. Higher Education Research \& Development, 31(1), 21-37.

Young, R. (2008). Language and interaction: An advanced resource book. London: Routledge. 
Table 1: Views of culture (based on Holliday, 2011, p. 5)

\begin{tabular}{|l|l|}
\hline Essentialist views & Non-essentialist views \\
\hline culture as physical space & culture as social force \\
language & culture is complex, its characteristics are \\
People in one culture are considered & Blurred boundaries, culture flows and \\
different to people in another & changes, no national boundaries \\
Neo-essentialist variation: diversity can & \\
make exceptions to the rule possible & \\
\hline
\end{tabular}

Table 2: Data by institution and phase of the project

\begin{tabular}{|c|c|c|}
\hline Institution & Phase 1 (Oct-Nov 2016) & Phase 2 (Mar-Apr 2017) \\
\hline Bournemouth & 4 & 4 \\
\hline Northumbria & 15 & 5 \\
\hline Nottingham & 10 & 7 \\
\hline Surrey & 16 & \\
\hline
\end{tabular}

